\title{
Multiple Emulsions - Preparation and Stability
}

Muschiolik, G., Scherze, I., Preissler, P., Weiss, J., Knoth, A. and Fechner, A. Friedrich-Schiller-University Jena, Institute of Nutrition, Dept. of Food Technology, Dornburger Str. 29, D-07743 Jena, Germany, muschiolik@t-online.de

\begin{abstract}
Multiple emulsions $\left(\mathrm{W}_{1} / \mathrm{O} / \mathrm{W}_{2}\right)$ with a long-term stability of at least 12 months were prepared in order to encapsulate low molecular weight bioactive substances $\left(M_{r}<2000 \mathrm{~g} / \mathrm{mol}\right)$. The influence of the emulsifying procedure, i.e. the variation in energy input for dispersing $\mathrm{W}_{1} / \mathrm{O}$ in $\mathrm{W}_{2}$, and the influence of the emulsion composition were investigated in relation to emulsion stability and encapsulation efficiency. In order to incorporate the $\mathrm{W}_{1} / \mathrm{O}$ into the $\mathrm{W}_{2}$ phase membrane emulsification, or low pressure emulsification, using a special orifice valve is favourable. A satisfactory coalescence stability of multiple emulsions with small oil droplets can be achieved by using proteins as $\mathrm{O} / \mathrm{W}$ emulsifiers instead of low molecular weight emulsifiers. For good emulsion stability and low leakage from the inner to the outer water phase, an osmotic gradient $\left(\sim 180-200 \mathrm{mOsmol} / \mathrm{kg}\right.$ ) between $\mathrm{W}_{1}$ and $\mathrm{W}_{2}$ is necessary. Long-term stable multiple emulsions enriched with bioactive or flavouring substances can be prepared with low and high dry matter in both aqueous phases by adding different carbohydrates. The stability and release properties can be tailored by varying the oil phase or by modifying the $\mathrm{O} / \mathrm{W}$ interface. PC depleted lecithin proved to be a suitable substitute for PGPR as an emulsifier for the effective dispersal of the $\mathrm{W}_{1}$ phase into the oil phase. Therefore, multiple emulsions offer the opportunity to enclose nutritional components for multidispersed functional foods.
\end{abstract}

\section{Keywords}

Multiple emulsion, double emulsion preparation, W/O/W, functional food, lecithin, PGPR, protein, membrane emulsification, encapsulation efficiency, osmotic gradient, coalescence stability, homogenizer principle

\section{Introduction}

Multiple emulsions are complex systems which consist of both water-in-oil $\left(\mathrm{W}_{1} / \mathrm{O}\right)$ and oil-inwater-emulsions $\left(\mathrm{O} / \mathrm{W}_{2}\right)$ at the same time. They are potential matrices for the encapsulation of bioactive compounds and for a controlled release of such compounds. In order to obtain a high yield of the inner $\mathrm{W}_{1}$ droplets, the emulsification of the $\mathrm{W}_{1} / \mathrm{O}$ emulsion into the outer $\mathrm{W}_{2}$ phase has to be performed under mild conditions. The influence of the dispersion method and of the composition of the formulation/phases (i.e. W/O emulsifier, $\mathrm{O} / \mathrm{W}$ emulsifier, concentration of solutes in the aqueous phases) on the properties of the $\mathrm{W} / \mathrm{O} / \mathrm{W}$ emulsion was examined by using different emulsifying devices such as a low pressure homogenizer with combined orifices system (combi-valve) and membrane emulsification device with microporous glass or ceramic (Muschiolik, 2005; Scherze et al., 2005; Muschiolik \& Bunjes, 2006).

\section{Preparation of multiple emulsions}

For the preparation of W/O emulsions, polyglycerol polyricinoleate (PGPR) or fractionated lecithin was used as an emulsifier together with MCT-oil or sunflower oil. For the preparation 
and stabilization of multiple emulsions, proteins and protein-polysaccharide-conjugates were applied.

Although no leakage of the $\mathrm{W}_{1}$ phase into $\mathrm{W}_{2}$ phase occurs during membrane emulsification (Fig. 1), the combi-valve system (Fig. 2B) is also suitable for homogenizing a premix of multiple emulsions with a high yield from the inner water phase $(\sim 97 \%)$ at a low operating pressure $(1 \mathrm{MPa})$.

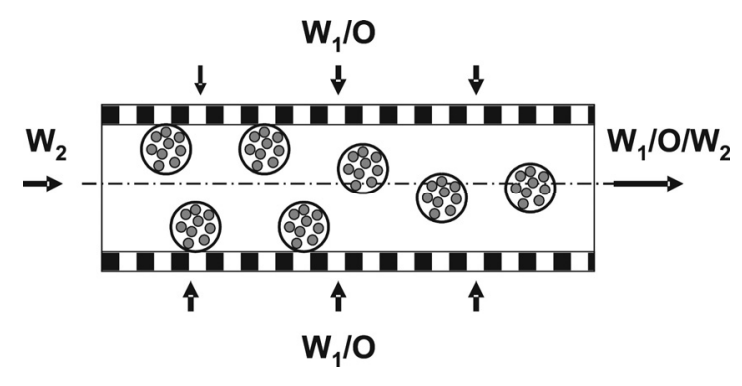

Figure 1: Preparation of multiple emulsion by membrane emulsification

A

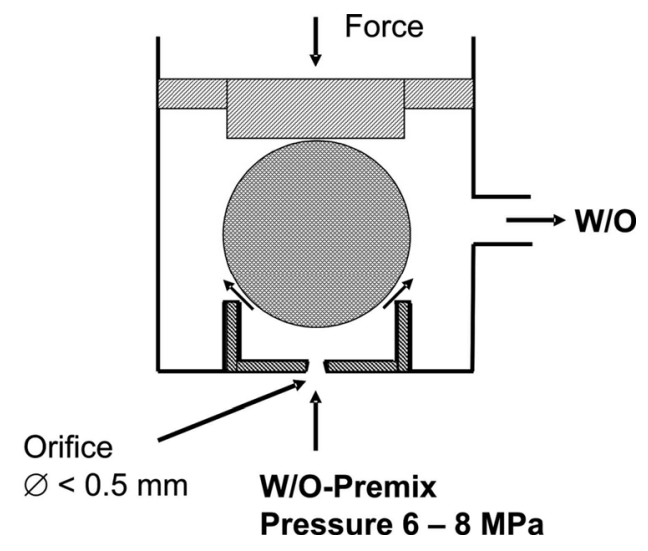

B

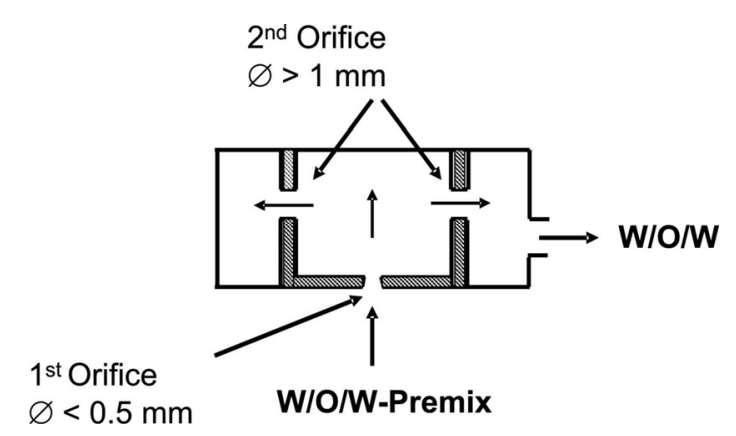

Figure 2: Homogenizing systems for preparing fine W/O-emulsion (A, combined orifice with ball valve, "ball valve") and $\mathrm{W} / \mathrm{O} / \mathrm{W}$ emulsion by homogenizing a $\mathrm{W} / \mathrm{O} / \mathrm{W}$ premix (B, combined orifices "combi-valve"; Muschiolik, 2005)

Other emulsifying systems such as the conventional high pressure homogenizer (i.e. EmulsiFlex C5) and the ball-valve system (Fig. 2A) lead to very unstable multiple emulsions with a low yield from the inner water phase and are, therefore, not so suitable for the preparation of multiple emulsions (Fig. 3). 


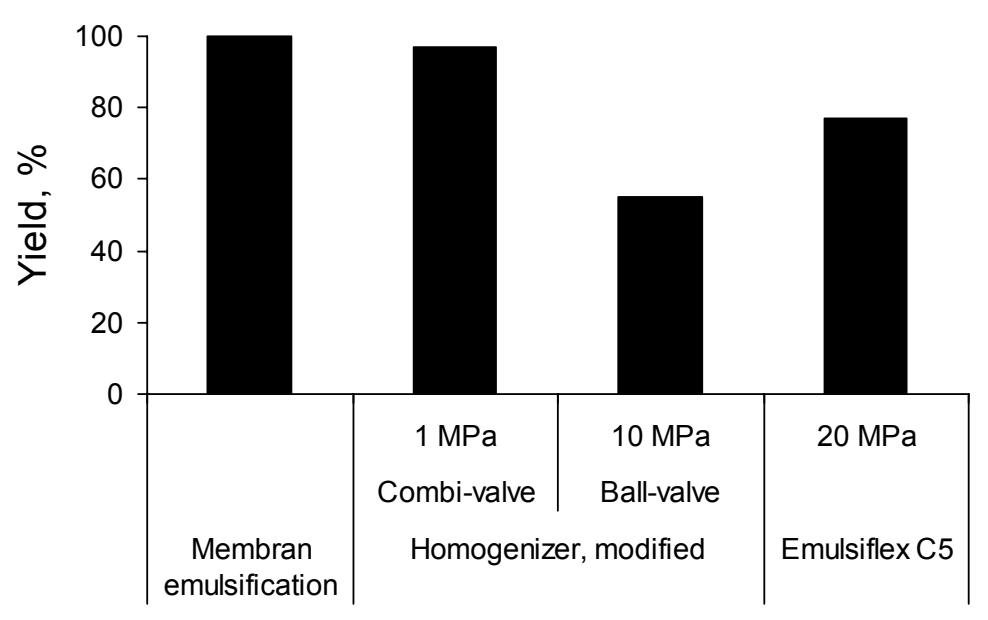

Figure 3: Influence of the emulsifying devices on the stability of $\mathrm{W}_{1}$ in $\mathrm{W}_{1} / \mathrm{O} / \mathrm{W}_{2}$ (yield)

\section{Emulsion stability and encapsulation behaviour}

When choosing the appropriate compositions of the phases and appropriate preparation conditions, multiple emulsions with high storage stability can be obtained (high yield of the $\mathrm{W}_{1}$ phase, no phase alteration, no phase separation during 8 month at $+7^{\circ} \mathrm{C}$ ). Moreover, in order to obtain multiple emulsions with high yield and low release of encapsulated substances, the electrolyte concentration and, therefore, the osmotic gradient between the two aqueous phases ( $\sim 180$ to $200 \mathrm{mOsmol} / \mathrm{kg}$ ) has to be adjusted to an optimum level.

\section{Addition of $\mathrm{NaCl}$ and gelatine to the $W_{1}$-phase}

The addition of $\mathrm{NaCl}$ was essential to achieve coalescence-stable W/O emulsions prepared with PGPR. On the other hand, the presence of gelled gelatine prevented water droplet coalescence in PGPR-stabilized emulsions without $\mathrm{NaCl}$ during the investigated storage time. This stabilizing effect of $\mathrm{NaCl}$ and gelatine increased the encapsulation efficiency and the oil droplet stability of the multiple emulsions. Due to partial water transfer from the $\mathrm{W}_{1}$ - to the $\mathrm{W}_{2}$-phase, the emulsions containing $\mathrm{NaCl}$ in the $\mathrm{W}_{1}$-phase exhibited a higher oil droplet diameter after preparation (Fig. 4). During storage the emulsions without $\mathrm{NaCl}$ showed a rapid coalescence of oil droplets. The long-term stability of multiple emulsions requires a balance between the Laplace and the osmotic pressure.

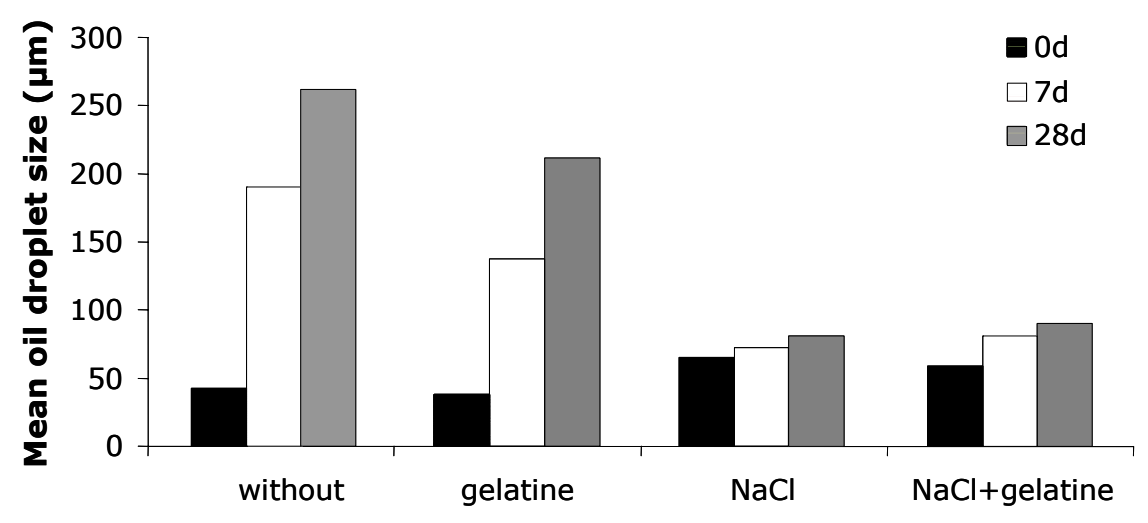

Additives to $\mathbf{W}_{1}$

Fig. 4: Effect of $\mathrm{NaCl}$ and gelatine on the oil droplet diameter of multiple emulsions during storage ( $4 \%$ PGPR in sunflower oil, $1 \% \mathrm{WPI}$ in $\mathrm{W}_{2}, \mathrm{~W} / \mathrm{O}=20 / 80$ by means of rotorstator system with $\mathrm{d}_{43}=1.1 \mu \mathrm{m} ; \mathrm{W}_{1} / \mathrm{O}$ in $\mathrm{W}_{2}=15 / 85$ by means of micropores SPG with $\left.d_{p}=4 \mu \mathrm{m}\right)$ 
The essential effect of $\mathrm{NaCl}$ and gelatine was also visible in the microscopic images (Fig. 5). In the case of additives in the $\mathrm{W}_{1}$-phase, the filling level of oil droplets with $\mathrm{W}_{1}$ showed only minor changes within 8 month. On the other hand, the emulsions without additives already exhibited less inner water droplets after one day of storage.
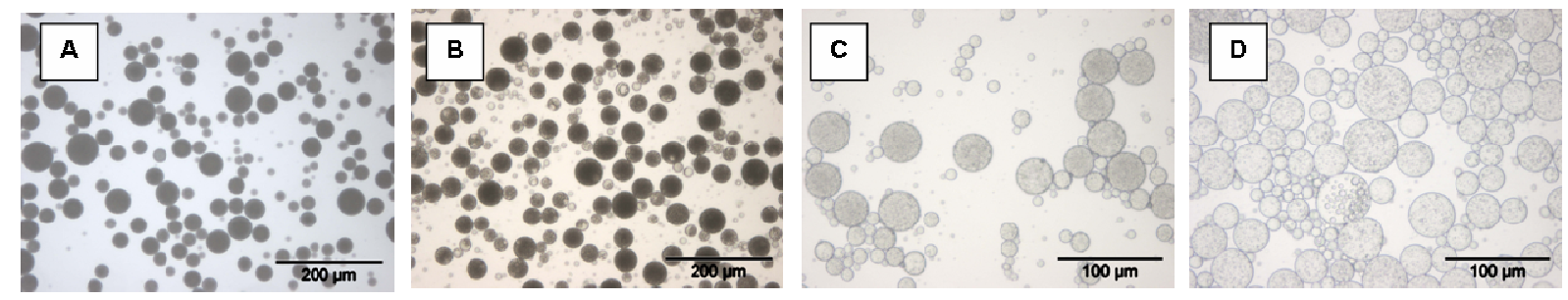

Fig. 5: Microscopic images of multiple emulsions. A: $\mathrm{NaCl}+$ Gelatine in $\mathrm{W}_{1}$, after preparation; $\mathrm{B}: \mathrm{NaCl}+$ Gelatine in $\mathrm{W}_{1}$, after 8 months of storage; $\mathrm{C}$ : without additives in $\mathrm{W}_{1}$, after preparation; $\mathrm{D}$ : without additives in $\mathrm{W}_{1}$, after 1 day of storage.

\section{Effect of membrane emulsification}

Membrane emulsification (Fig. 1) results in multiple emulsions with a yield from the $\mathrm{W}_{1^{-}}$phase of close to $100 \%$ as determined by the release of the high molecular weight dye Poly R478 and a tailored particle size range. In order to obtain different emulsion properties, i.e. an external oil droplet size from 5 to $50 \mu \mathrm{m}$, the process parameters of the second emulsification step using microporous membranes have to be varied.

In order to prepare multiple emulsions, the hydrophilic membrane for the second step has to have a micropore size greater than or equal to twice the diameter of the internal water droplets of the $\mathrm{W} / \mathrm{O}$ emulsion. Under the experimental conditions of this investigation, the internal $\mathrm{W}_{1}$ droplet sizes were $<1.5 \mu \mathrm{m}\left(\mathrm{d}_{43}=1.1 \mu \mathrm{m}\right)$. Hence, membranes with a mean pore size of $d_{p}=$ 4 or $5 \mu \mathrm{m}$ were used for multiple emulsion preparation.

Proteins are suitable emulsifiers for creating coalescence-stable multiple emulsions at low energy input. The particle size of protein-stabilised oil-in-water emulsions made by micropores is determined by the mean pore diameter of the membranes, the velocity of the continuous phase (i.e. the wall shear stress), and the transmembrane pressure (i.e. the flux of the disperse phase).

The disperse phase (i.e. the primary $\mathrm{W}_{1} / \mathrm{O}$ emulsion) had a constant viscosity of $130 \mathrm{mPa}$. The disperse phase flux was adjusted by changing the transmembrane pressure. Operating with a membrane of $d_{p} 4 \mu \mathrm{m}$ at a velocity of the continuous phase of $1.97 \mathrm{~m} \mathrm{~s}^{-1}$, the external mean particle diameter $\left(\mathrm{d}_{43}\right)$ of multiple emulsions containing only milk protein in the continuous $\mathrm{W}_{2}$-phase increased from 56.9 to $72.7 \mu \mathrm{m}$ as the disperse phase flux was increased from 64.3 to $214 \mathrm{~L} \mathrm{~m}^{-2} \mathrm{~h}^{-1}$.

The droplet size of $\mathrm{W}_{1} / \mathrm{O}$-droplets can be influenced by the wall shear stress of the continuous phase $\mathrm{W}_{2}$ and the wall shear stress can be adjusted by varying the velocity and viscosity of the continuous phase. Using milk protein as the surface-active substance and PEG to adjust the viscosity of the $\mathrm{W}_{2}$-phase, the mean droplet size of the O-phase decreased with increasing viscosity when the flow rate of the continuous phase was kept constant. At a viscosity $<2 \mathrm{mPa}$, external mean droplet diameters $\left(\mathrm{d}_{43}\right)$ of 50 to $60 \mu \mathrm{m}$ were attained for the protein- 
stabilized multiple emulsions, whereas they decreased to $5 \mu \mathrm{m}$ at a viscosity of $180 \mathrm{mPa} \mathrm{s}$ (Scherze et al. 2005).

\section{Multiple emulsions with high sugar content in the aqueous phases}

$\mathrm{W}_{1} / \mathrm{O}$-emulsions with PGPR as an emulsifier were prepared by pressure homogenizing at $8 \mathrm{MPa}$ (homogenizer Fig. 2A, water droplets $<1 \mu \mathrm{m}$ ). The second emulsifying step (preparation of $\mathrm{W}_{1} / \mathrm{O} / \mathrm{W}_{2}$ with a high yield of $\mathrm{W}_{1}$ ) was carried out at $0.7 \mathrm{MPa}$ homogenization pressure with the combi-valve system (homogenizer Fig. $2 \mathrm{~B}$ ). The $\mathrm{W}_{2}$-phase contained whey protein isolate (WPI) as a hydrophilic emulsifier.

Depending on the sucrose concentration, the multiple oil droplet size of the $\mathrm{W} / \mathrm{O} / \mathrm{W}$ emulsion varied between 7 and $10 \mu \mathrm{m}$. The droplets of emulsions swelled during 28 days of storage reaching sucrose concentrations of $20 \%$, whereas the particle size distribution did not change at higher sucrose concentrations.

Long-term stable multiple emulsions enriched with bioactive or flavouring substances can be prepared with low and high dry matter in both aqueous phases by adding different carbohydrates. The osmolality of the ingredients used, which is important for system stability, is shown in Figure 6.

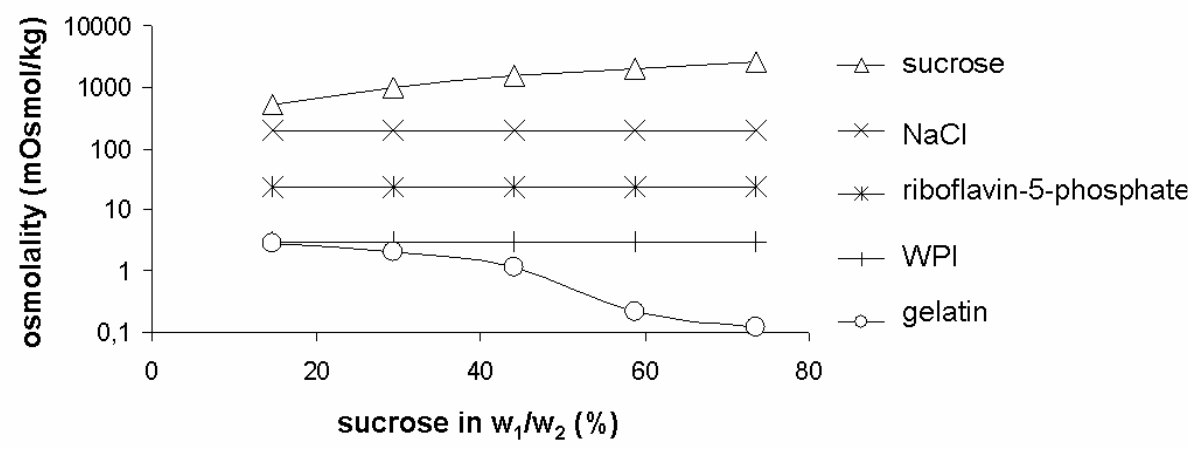

Figure 6: Influence of the components in $\mathrm{W} / \mathrm{O} / \mathrm{W}$ on the osmolality. Composition of $\mathrm{W}_{1}$ : sucrose $(14.7-73.5 \%), \mathrm{NaCl}(0.6 \%$ of water content), gelatine type A Bloom 260 ( $3 \%$ of water content); $\mathrm{W}_{2}$ : sucrose $(14.7-73.5 \%)$, whey protein isolate (WPI, $1 \%$ of water content) 


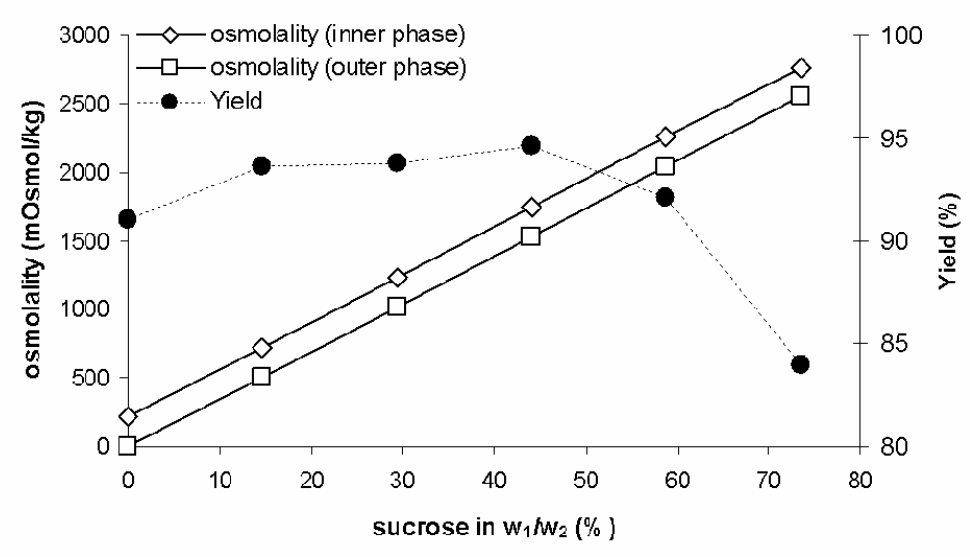

Figure 7: Influence of sucrose concentration on osmolality of $\mathrm{W}_{1}$ and $\mathrm{W}_{2}$ and on the yield of vitamin $\mathrm{B}_{2}$ (riboflavine-5-phosphate) in $\mathrm{W}_{1}$-Phase

For such multiple emulsions enriched in sugar content it can be stated that:

The production of small water droplets $(<1 \mu \mathrm{m})$ and stable multiple emulsions is possible up to a sucrose content of $58.8 \%$ in the water phase.

$>$ Small water droplets $(<1 \mu \mathrm{m})$ are necessary for producing stable $\mathrm{W} / \mathrm{O} / \mathrm{W}$ emulsions with a high yield from the inner water phase.

$>$ The water activity of multiple emulsions can vary between 0.75 and 1.0 with respect to the sucrose content, the lipid phase, and the storage temperature.

The water activity of multiple emulsions with respect to the sugar content is shown in Figure 8.

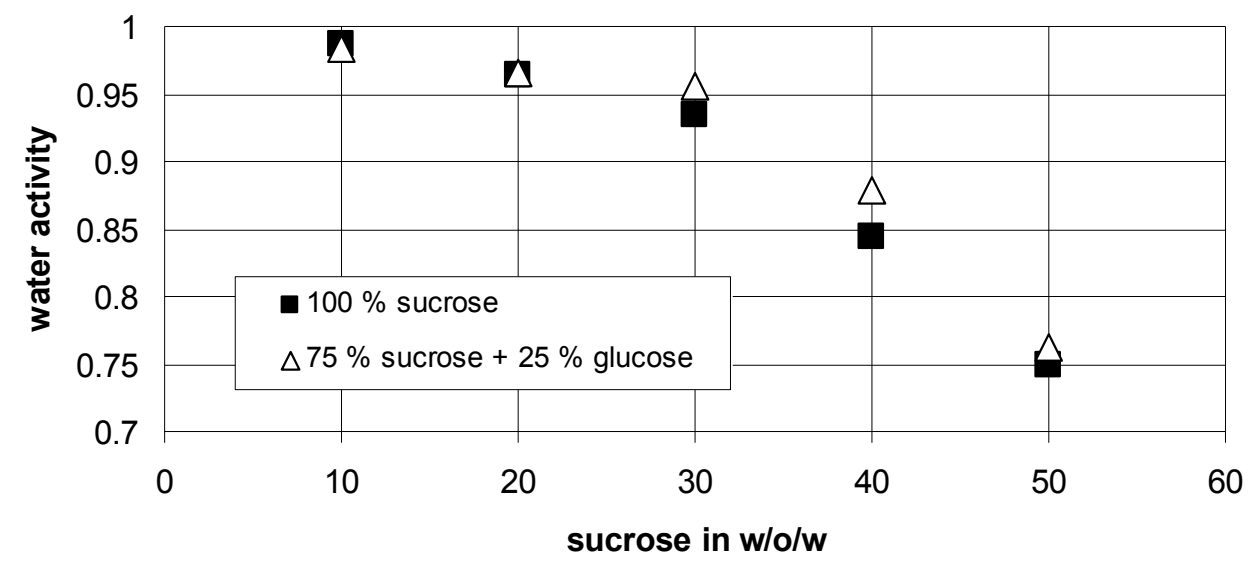

Figure 8: Water activity of multiple emulsions with respect to the sugar content in the water phases

Figure 9 demonstrates the particle size of multiple emulsion oil globules (A, fresh; B, 28 days of storage at $7{ }^{\circ} \mathrm{C}$ ). 
A

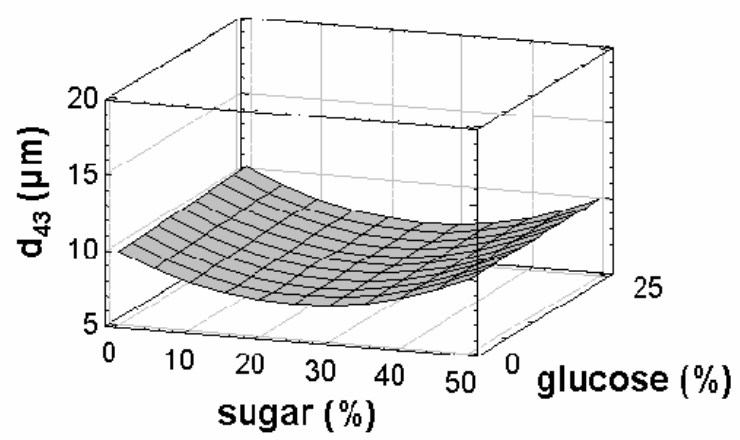

B

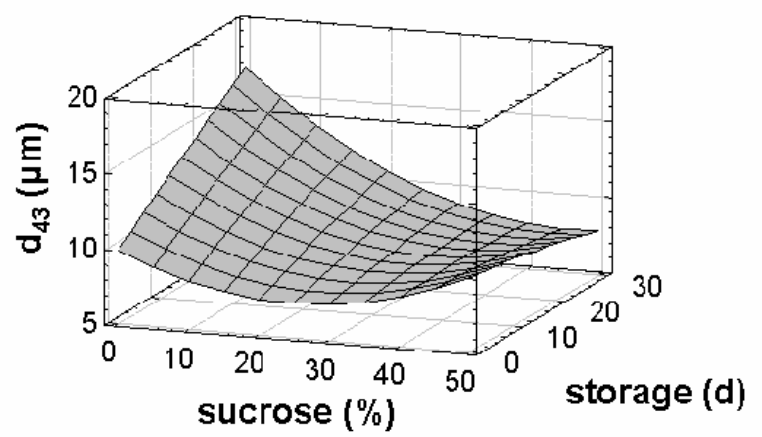

Figure 9: Oil globule size $\left(\mathrm{d}_{4,3}\right)$ of the $\mathrm{W} / \mathrm{O} / \mathrm{W}$ with respect to the sugar content $(\mathrm{A})$ and to the sucrose content and storage time (B); Preissler et al., 2005

The yield of encapsulated vitamin $B_{2}$ is higher at sugar concentrations of about 20 to $40 \%$ (encapsulation capacity of multiple emulsions $>80 \%$, Fig. 10).

A

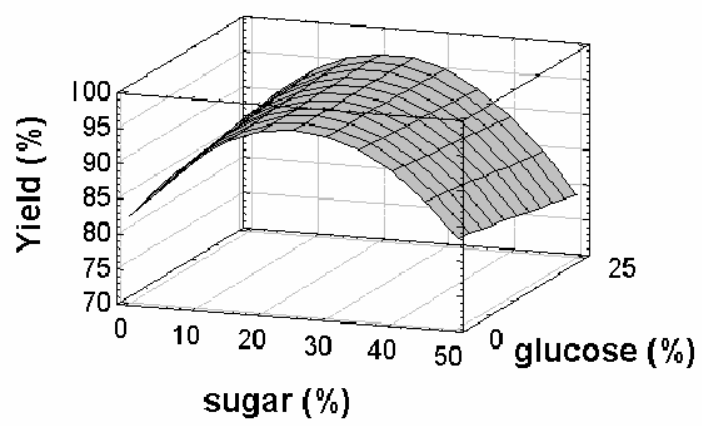

B

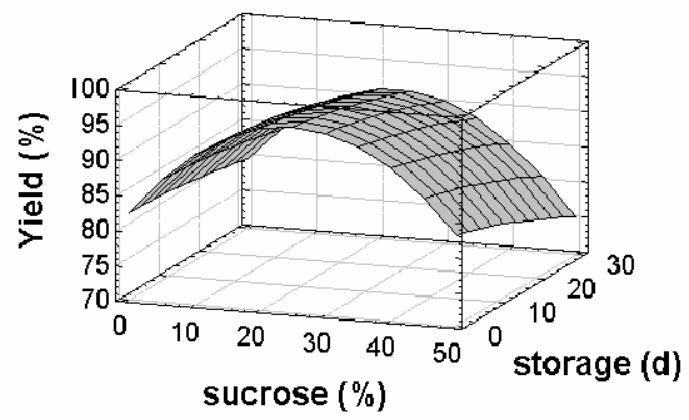

Figure 10: Yield of vitamin $\mathrm{B}_{2}$ in $\mathrm{W} / \mathrm{O} / \mathrm{W}$ with respect to the sugar content $(\mathrm{A})$ and the storage time (B)

\section{Influence of hydrophilic emulsifier}

Due to the higher surface activity, the use of sodium caseinate (SCN) and the low molecular surfactant Polysorbat 20 (P-20) resulted in smaller droplets after emulsion preparation by means of micro pores compared to the whey protein isolate (WPI) (Fig. 6). During storage only minor changes in droplet size were observed. Immediately after preparation the release of the model substance vitamin $\mathrm{B}_{12}$ varied between 6.6 and $8.5 \%$ independent of the emulsifier used. While the release of the model substance increased rapidly during storage in emulsions stabilized by the low molecular weight P-20, the high molecular weight proteins improved the encapsulation (Fig. 6).

The effect of the emulsifier on the filling level of oil droplets with $\mathrm{W}_{1}$ is seen in Fig. 11. After preparation all emulsions showed closely-packed droplets. The filling level of protein- 
stabilized emulsions remained nearly constant after storage. The emulsions stabilized by P-20 were characterized by a visible swelling of the inner droplets during storage. This can be attributed to an interaction between both emulsifiers, PGPR and P-20, and to the lower interfacial stability of the low molecular weight emulsifier as well.
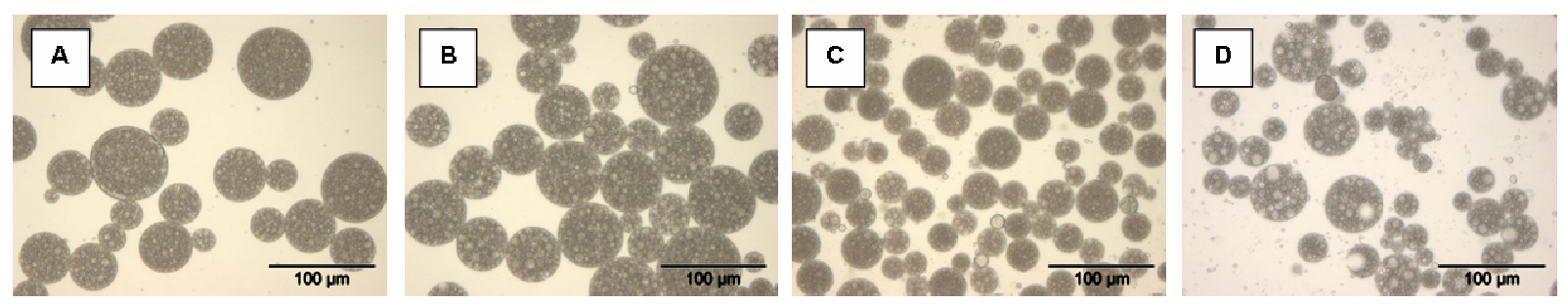

Figure 11: Microscopic images of multiple emulsions using protein (A, B) and Polysorbat 20 $(\mathrm{C}, \mathrm{D})$ as hydrophilic surface active agents, respectively. A; C: after preparation; $\mathrm{B}, \mathrm{D}$ : after one week storage.

\section{Modifying $\mathbf{O} / \mathbf{W}_{2}$-interface with protein-polysaccharide-conjugates}

Proteins such as sodium caseinate (SC) are reported to be excellent emulsifiers in $\mathrm{O} / \mathrm{W}$ emulsions. However, the industrial application of both proteins and multiple emulsions is limited due to their instability against heat, organic solvents, and changes in $\mathrm{pH}$ value (Kato, 1996). Conjugates of proteins and polysaccharides with a high molecular weight combine the properties of a hydrophobic protein, i.e. being firmly attached to the oil droplet surface, with the properties of a hydrophilic polysaccharide, i.e. being highly solvated by the aqueous phase medium (Dickinson \& Galazka, 1991). The creation of such conjugates is based on a Maillard-type reaction where the amino groups of a protein react with the carboxyl group of a polysaccharide by forming covalent amide bonds (Kato et al., 1990). These bonds are very stable against changes in $\mathrm{pH}$ value, temperature or ionic strength (Dickinson \& Euston, 1991). Such glycoproteins unite the good emulsifying properties of the proteins with the resistance against acidic conditions of the polysaccharides. Fechner et al. (2005) compared the emulsifying properties of sodium caseinate with conjugates of SC and dextran in multiple emulsions under neutral, acidic, and heated conditions, respectively.

To prepare the conjugate the SC was combined with Dex $\left(M_{r} 500,000 \mathrm{~g} / \mathrm{mol}\right)$ in a mixing ratio of $1: 3$ and incubated at $60^{\circ} \mathrm{C}$ and a humidity of $79 \%$ for $8 \mathrm{~h}$. The multiple emulsions, with encapsulated vitamin $\mathrm{B}_{12}$ in the inner $\mathrm{W}_{1}$-phase, were prepared using a two-step emulsification technique. Whereas different amounts of PGPR were used as the hydrophobic emulsifier, the conjugate and the SC alone were used as the hydrophilic emulsifiers.

The usage of the conjugate in the multiple emulsions instead of pure protein led to the formation of smaller oil droplets and a narrower particle size distribution. Furthermore, improved stability against aggregation and coalescence under acidic conditions was observed (Figure 12). 

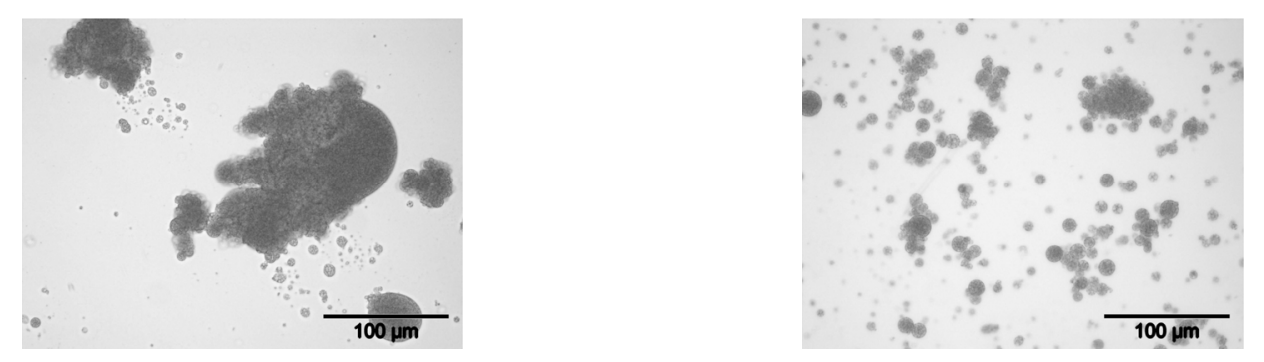

Figure 12: Microscopic images of the $\mathrm{W}_{1} / \mathrm{O} / \mathrm{W}_{2}$-emulsions ( $8 \% \mathrm{PGPR}$ ) at $\mathrm{pH} 4.0$ with $\mathrm{SC}$ (left), or SC-Dex500 (right) as hydrophilic emulsifier (Fechner et al., 2005)

Despite the coalescence of the oil droplets of the multiple emulsions with SC in emulsions with $8 \%$ PGPR, the release of vitamin $\mathrm{B}_{12}$ into the $\mathrm{W}_{2}$-phase after treatment with acid or heat and during storage was not significantly increased when the SC-Dex500 was used as a hydrophilic emulsifier.

In emulsions containing only $2 \%$ PGPR in O the use of SC-Dex500 conjugates instead of the pure protein depressed the vitamin release significantly after acidification and heating as well as during storage (Fig. 13). A reason for the higher encapsulation efficiency could be a more stable interfacial film caused by using the SC-Dex500 instead of the pure protein.

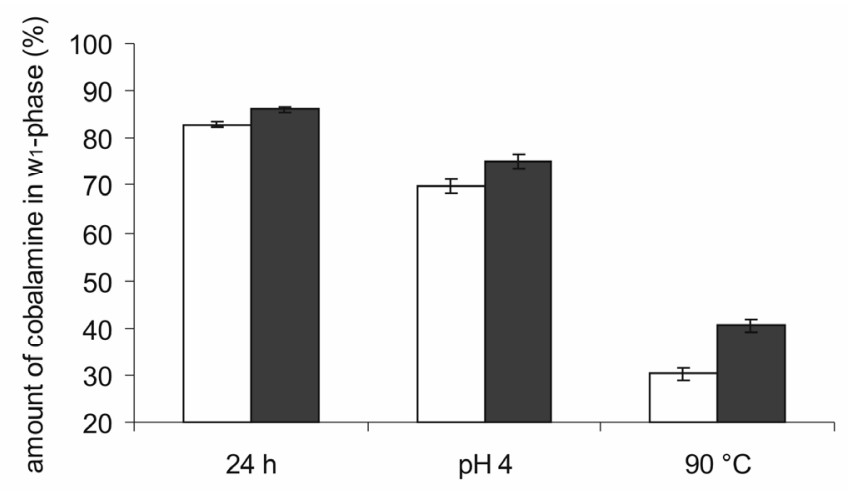

Figure 13: Yield of the $\mathrm{W}_{1}$-phase after $24 \mathrm{~h}$, acidification $(\mathrm{pH} 4.0)$ or heating $\left(90^{\circ} \mathrm{C}\right.$, $10 \mathrm{~min}$ ); W/O/W-emulsions with 2\% PGPR in the O-phase; ( $\square$ ) SC, (匹) SCDex500

In the case of $8 \%$ PGPR in $\mathrm{O}$, the release of vitamin $\mathrm{B}_{12}$ during dialysis from acidified multiple emulsions was comparably low for both SC and SC-Dex conjugate as an O/W emulsifier. At lower PGPR concentration (2\%) in acidified multiple emulsions, the release of vitamin into the surrounding water significantly decreased from $40 \%$ to $30 \%$ when SC-Dex was used instead of SC as an O/W emulsifier (Fig. 13). In untreated and heated emulsions no significant differences could be observed. 


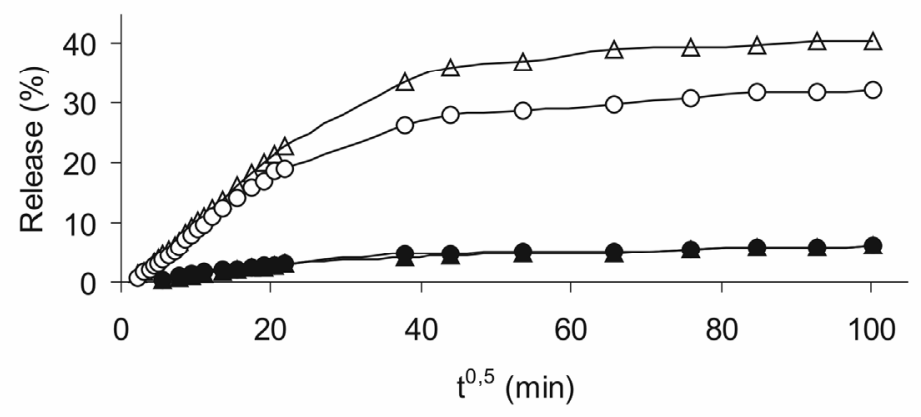

Figure 14: Vitamin $\mathrm{B}_{12}$ release into the surrounding water $\left(\mathrm{W} / \mathrm{O} / \mathrm{W}\right.$ at $\left.\mathrm{pH} 4.0 ; \mathrm{t}^{0.5} 100=7 \mathrm{~d}\right)$;

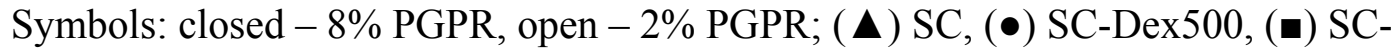
Dex500-0

The improvement in the encapsulation efficiency of vitamin $\mathrm{B}_{12}$ in the multiple emulsions from using only $2 \%$ PGPR as a hydrophobic emulsifier offers the opportunity to increase the inclusion of bioactive components even at low emulsifier concentrations in the oil phase. Protein-polysaccharide conjugates enable the preparation of stable emulsions, especially against changes of environmental conditions such as $\mathrm{pH}$ or temperature. At present very little has been done in the use of protein-polysaccharide conjugates in multiple emulsions.

\section{Effect of PGPR on emulsion properties}

While the particle size of w/o emulsions increased as expected with decreasing PGPR-content $\left(\mathrm{d}_{43}: 0.95 \mu \mathrm{m}, 1.14 \mu \mathrm{m}, 1.59 \mu \mathrm{m}, 2.80 \mu \mathrm{m}, 4.46 \mu \mathrm{m}, 4.96 \mu \mathrm{m}\right)$, the PGPR content showed no effect on the oil droplet size of the multiple emulsions (emulsification by means of orifice valves: $8.6 \mu \mathrm{m}$; by means of micropores: $34.2 \mu \mathrm{m}$ ). Increasing the PGPR content resulted in higher encapsulation efficiencies of the high molecular weight dye (Poly R-478) as well as the vitamin $\mathrm{B}_{12}$ (Fig. 15). A PGPR content below $2 \%$ led to higher permeation of encapsulated substances during storage. Under the conditions used a minimum PGPR content of $4 \%$ was necessary to obtain multiple emulsions with limited release of encapsulated substances.

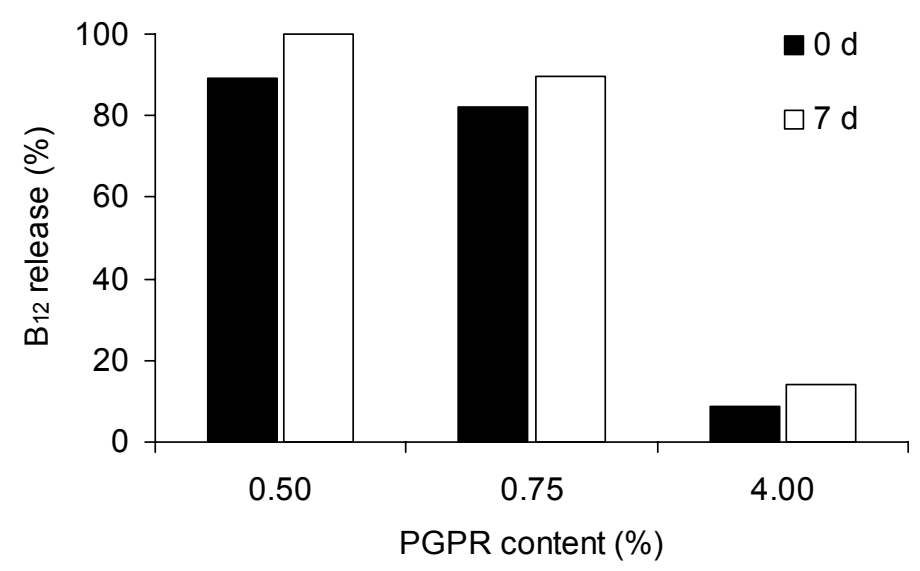

Figure 15: Influence of the content of PGPR in the oil phase on release of vitamin $B_{12}$ immediately after preparation of multiple emulsion as well as after storage for 7 days 


\section{Substitution of PGPR by lecithin}

In general, the production of W/O emulsions requires the use of emulsifiers like PGPR which have to be declared. In accordance with a strong reduction of the interfacial tension, such PGPR-stabilized W/O emulsions show only small differences in water droplet size distribution when the lipid phase-composition changes (Fig. 16). Because of the absence of droplet aggregates, these emulsions behave like low viscous and almost Newtonian fluids. In order to prepare multiple emulsion systems (W/O/W) for "Functional Food" applications (such as the encapsulation of micronutrients and bioactive substances in the inner water phase), it is preferable that only natural additives be used to support the formation and stabilisation of the emulsions.

Hydrophobic lecithin with a reduced PC content, which favours the stabilization of W/O emulsions, could provide such an alternative. Under the conditions used in the investigation, the application of PC-depleted lecithin as an emulsifier led to the formation of droplets similar to those produced by PGPR when sunflower oil or olive oil was used as the continuous phase. However, when prepared with PC-depleted lecithin as emulsifier, the properties of the emulsions depended more strongly on the lipid composition of the continuous phase. When prepared with MCT-oil (medium chain triglycerides) as continuous phase, the water droplets of these lecithin-stabilized emulsions were distributed almost singly and were significantly larger than with oils which contained long-chain fatty acids (sunflower oil or olive oil). The use of butter oil reduced water droplet size even further (Figure 16).

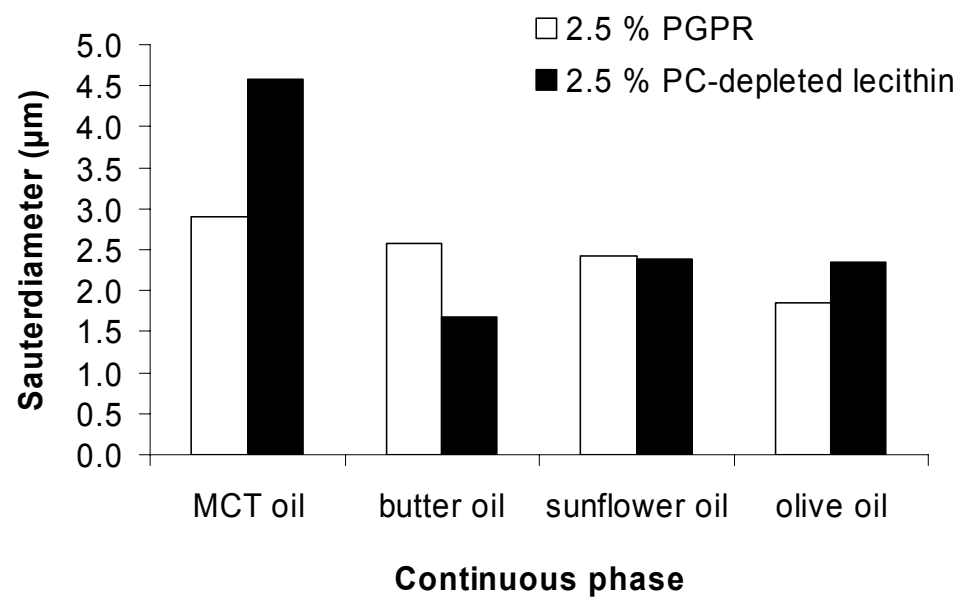

Figure 16: Influence of the lipid type and the emulsifier on the particle diameter $\left(\mathrm{d}_{3,2}\right)$ of $\mathrm{W} / \mathrm{O}$ emulsions (Knoth et al., 2005a)

The droplets of lecithin-stabilized emulsions formed large aggregates when lipids with longchain fatty acids such as sunflower or olive oil were used as continuous phase. The droplets were not visible as single droplets but as lumps (Fig. 17, A). Disintegration of such aggregates into single droplets only occurred during shearing (Knoth et al., 2005b). Due to their strong water droplet association, these emulsions were very viscous. It is known that the flocculation of $\mathrm{W} / \mathrm{O}$ emulsions is induced by the presence of long-chain lipids in the continuous phase (Leal-Calderon, 1997). Perrin (2000) described the formation of fractal structure as a result of droplet aggregation in $\mathrm{W} / \mathrm{O}$ emulsions. The rheological parameters reflected this interaction between the water droplets. Whereas the non-aggregated MCT-containing emulsions showed 
a low viscosity which decreased only slightly with increasing shear rate, the other emulsions displayed yield stress and a strong shear-thinning flow behaviour (Fig. 17, B).

The observations of the emulsion droplet sedimentation conformed to the measurements of the emulsion viscosity in so far as they showed that high viscosity is an important factor in emulsion stability. Due to water droplet interaction in emulsions with sunflower, olive, and butter oils, the high viscosity prevented the sedimentation of water droplets. There was a significant phase separation due to sedimentation in emulsions containing MCT-oil. The sedimentation of water droplets in W/O emulsions with only MCT-oil is due to the larger droplet size as well as the low viscosity (Knoth et al., 2005a).

A

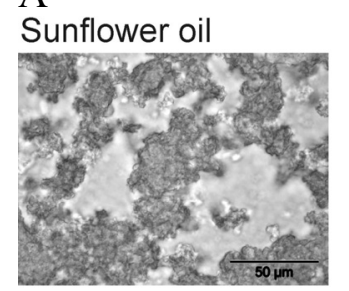

MCT oil

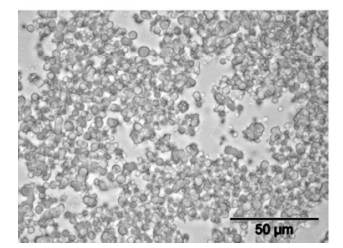

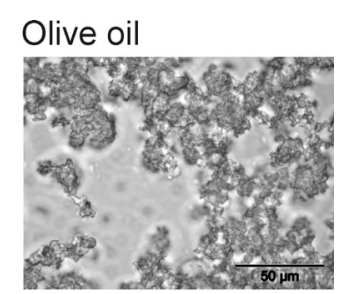

Butter oil

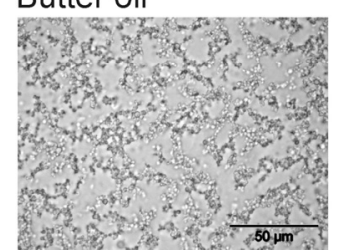

$\mathrm{B}$

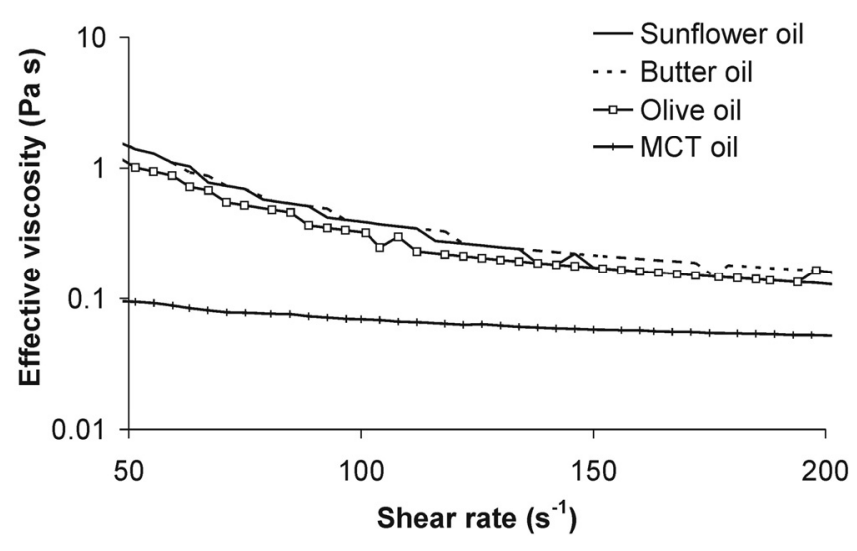

Figure 17: Influence of the lipid type on the aggregation (A) and the rheological behaviour (B) at $50^{\circ} \mathrm{C}$ of emulsions with $2.5 \%$ lecithin as emulsifier

Proteins in solution can interact with surfactants to form surfactant-protein-complexes and might improve the stability of W/O emulsions. The incorporation of a thickening or gelling polymer (e.g. xanthan, gelatine) within the dispersed aqueous phase of a W/O emulsion has also been proposed as a way of improving long-term-stability. Because of this, W/O emulsions with PC-depleted lecithin as emulsifier and different milk proteins (whey protein isolate, WPI; sodium caseinate, SC) or the polysaccharide xanthan diluted in the dispersed phase were prepared (Knoth et al., 2005b). Combining this lecithin with SC led to a stronger and more effective decrease in interfacial tension between water and oil than by WPI, whereas the interfacial acitvitiy of the lecithin was not significantly influenced by the xanthan. However, in comparison to the $\mathrm{W} / \mathrm{O}$ emulsion without protein, the addition of SC led to a drastic increase in water droplet size and to a visible sedimentation of the dispersed phase after 7 days of storage.

The rapid adsorption of the excellent oil-in-water emulsifier SC at the interface might hinder the adsorption of the emulsifier lecithin. In contrast, emulsions with WPI contained smaller water droplets and showed improved stability of the dispersed phase against sedimentation, even after 2 month of storage (Fig. 18).

The increased mechanical stability of adsorption layers containing both $\beta$-lactoglobulin and phosphatidylcholine or phosphatidyl-ethanolamine was reported by Wüstneck et al. (2001) and Yi Zhang et al. (2003). Thus it is possible that WPI supports the emulsifying process and strengthens the stability of $\mathrm{W} / \mathrm{O}$ emulsions. 
Increasing the consistency factor of the dispersed phase to $150 \mathrm{mPa} \mathrm{s}$ (at $50^{\circ} \mathrm{C}$ ) by $0.2 \%$ xanthan led to the formation of smaller water droplets, particularly in combination with WPI (Fig. 19). Thus, the increased viscosity of the water phase reduced the rates of droplet coalescence during homogenizing and storage. Despite the differences in particle size distribution, the $\mathrm{W} / \mathrm{O}$ emulsions showed no differences in the coalescence factor or in the sedimentation of the dispersed phase over a period of 7 days (Knoth et al. 2005b).

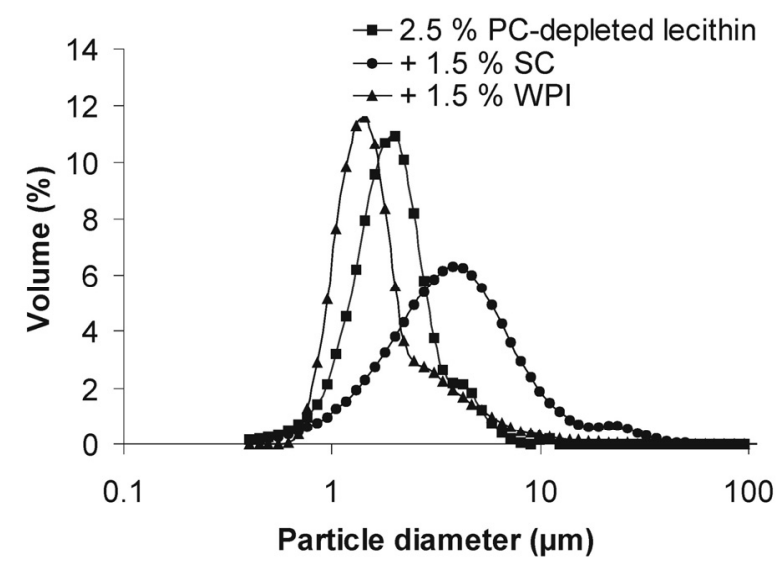

Figure 18: Particle size distribution of W/O emulsions stabilised by PC-depleted lecithin with respect to the protein in the aqueous phase

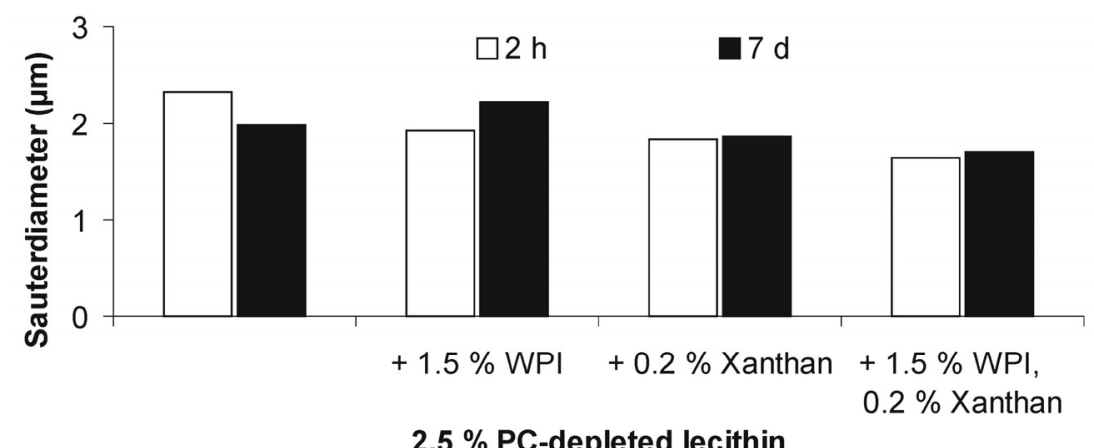

Figure 19: Sauterdiameter $\left(\mathrm{d}_{32}\right)$ of W/O emulsions stabilised by PC-depleted lecithin with respect to the composition of the dispersed phase

W/O emulsions prepared with lecithin in sunflower oil are stabler over a longer term with the combined addition of WPI and XPS to the water phase. This combination increases the viscosity of the water phase while inducing neither a strong reduction in interfacial tension nor a negative interaction with lecithin at the interface. However, adding unfolded proteins (gelatine, SC) with high surface activity to the water phase increased the instability of the $\mathrm{W} / \mathrm{O}$ emulsion with fractionated lecithin.

The results shown are the basis for preparing multiple emulsions that are stable in liquid systems with different dry matter and for preparing multiple emulsions incorporated in gelled food systems (Weiss et al., 2005). An example of such a gelled system which has been prepared by microparticulation of an alginate solution with multiple emulsion (MEBEADS ${ }^{\circledR}$ ) is shown in Figure 20. 


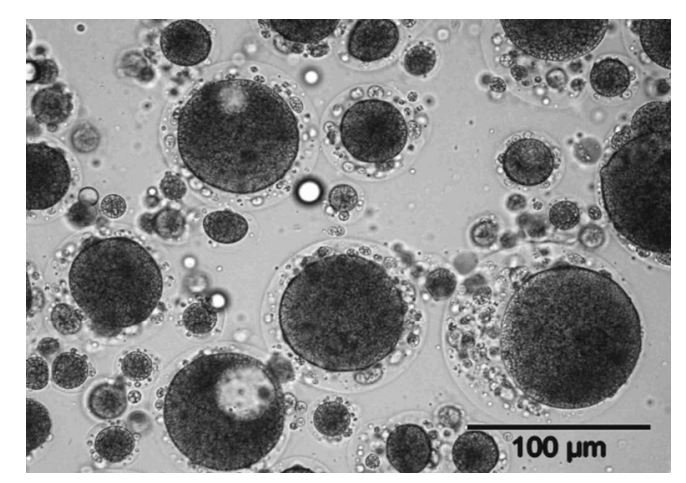

Figure 20: Microgels filled with multiple emulsion $\left(\operatorname{MEBEADS}^{\circledR}\right)$ as a supplement containing bioactive components for Functional Foods (Muschiolik et al., 2004)

Multiple emulsions offer the opportunity to enclose nutritional and healthy components for new food systems such as functional foods.

\section{Acknowledgement}

This research was supported by the FEI (Forschungskreis der Ernährungsindustrie e.V., Bonn), the AiF, and the Ministry of Economics and Labour (AiF-Projects No.: 13064BR, 13393BR, 13179BG, 14087BG).

\section{References}

Dickinson, E., Euston, S.R. (1991), Stability of food emulsions containing both protein and polysaccharide. In: Dickinson, E. (Ed.), Food polymers, gels and colloids. RSC, London, 132.

Dickinson, E., Galazka, V.B. (1991), Emulsion stabilization by ionic and covalent complexes of $\beta$-lactoglobulin with polysaccharides. Food Hydrocolloids 5, 281.

Fechner, A., Knoth, A. Scherze, I.,Muschiolik, G. (2005), Alternativemulgatoren - CaseinDextran-Konjugate zur Stabilisierung von Öl-in-Wasser-Emulsionen, Lebensmitteltechnik 37, Heft 10, 48.

Kato, A. (1996), Functional protein-polysaccharide conjugates. Comments on Agriculture and Food Chemistry 3, 139.

Kato, A., Sasaki, Y., Furuta, R., Kobayashi, K. (1990), Functional protein-polysaccharide conjugate prepared by controlled dry-heating of ovalbumin-dextran mixtures. Agricultural and Biological Chemistry 54, 107.

Knoth, A., Scherze, I., Muschiolik, G. (2005a), Effect of lipid type on water-in-oil-emulsions stabilized by phosphatidylcholine-depleted lecithin and polyglycerol polyricinoleate, European Journal of Lipid Science and Technology 107, 857.

Knoth, A., Scherze, I., Muschiolik, G. (2005b), Stability of water-in-oil emulsions containing phosphatidylcholine depleted lecithin, Food Hydrocolloids 19, 635.

Leal-Calderon, F., Mondain-Monval, O., Pays, K., Royer, N., Bibette, J. (1997), Water-in-oil emulsions: Role of the solvent molecular size on droplet interaction. Langmuir 13, 7008.

Muschiolik, G. (2005), Multidisperse Emulsionssysteme - Innovationspotential für Lebensmittel, Tagungsband 63. Diskussionstagung des Forschungskreises der Ernährungsindustrie, Innovationspotentiale in der Lebensmittelproduktion ", Universitäts-Buchdruckerei, Bonn, 39. 
Muschiolik, G., Bunjes, H. (Eds.), 2006: Herstellung und Eigenschaften von multiplen Emulsionen, Food, Pharma und Kosmetik, Behr's Verlag, Hamburg.

Muschiolik, G., Weiß, J., Scherze, I. (2004), Microgel as carrier, baking+sweets 4 (2),20.

Perrin, P. (2000) Droplet-droplet interactions in both direct and inverse emulsions stabilized by a balanced amphiphilic polyelectrolyte. Langmuir, 16, 881 .

Preissler, P., Knoth, A., Muschiolik, G. (2005), Einschluss bioaktiver Stoffe in Süßwarenfüllmassen, Süsswaren 50, Heft 12, 17.

Scherze, I., Knöfel, R., Muschiolik, G. (2005), Automated image analysis as a control tool for multiple emulsions, Food Hydrocolloids 19, 617.

Weiss, J., Scherze, I., Muschiolik, G. (2005), Polysaccharid gel with multiple emulsions, Food Hydrocolloids 19, 605-615.

Wüstneck, R., Moser, B., Karageorgieva, V.V., Muschiolik, G., Brehmer, L. (2001), Influence of lipids on interfacial dilatational behaviour of adsorbed ß-lactoglobulin layers. In E.Dickinson and R.Miller (Eds.), Food Colloids Fundamentals of Formulation, RSC Spec. Publ. No. 258, Cambridge, 198.

Yi Zhang, Zhihua An, Guangchen Cui, Junbai Li (2003), Stabilized complex film formed by co-adsorption of $\beta$-lactoglobulin and phospholipids at liquid/liquid interface. Colloids and Surfaces A: Physicochemical and Engineering Aspects, 223, 11. 